\title{
Dos livros didáticos para os cadernos de matemática: a emergência dos saberes profissionais
}

\author{
From textbooks to notebooks for school mathematics: \\ the emergence of the professional knowledge
}

Wagner Rodrigues Valente ${ }^{1}$

\begin{abstract}
Resumo
O texto analisa a emergência dos saberes profissionais do professor que ensina matemática a partir da inclusão de novas referências que são constituídas no estado de São Paulo, desde finais do século XIX. A análise leva em consideração as categorias "saber a ensinar" e "saber para ensinar" vindas de estudos que conjugam o desenvolvimento histórico-didático da formação de professores. Como documentos de pesquisa o estudo lança mão de livros didáticos e cadernos de aulas indicados para o trabalho dos professores que ensinam matemática. Os resultados do estudo mostram que a passagem de uma cultura do ensino secundário para o estabelecimento de uma formação profissional do professor tem lugar nos saberes objetivados pelos novos materiais, pelos cadernos de aulas. Tais materiais configuram saberes pedagógicos, saberes para ensinar, a "matemática para ensinar" como referência profissional do professor que ensina matemática.
\end{abstract}

Palavras-chave: matemática a ensinar; matemática para ensinar; livro didático de matemática; formação de professores que ensinam matemática.

\begin{abstract}
The text analyzes the emergence of the professional knowledge of the teacher who teaches mathematics from the inclusion of new references that are made in the state of São Paulo, since the late nineteenth century. The analysis takes into account the categories "knowledge to teach" and "knowledge for teach" coming from studies that combine the historical and educational development of teacher training. As research documents the study makes use of textbooks and notebooks classes suitable for the work of teachers who teach mathematics. The study results show that the passage of a secondary school culture for the establishment of a professional qualification of teachers takes place in the knowledge objectified by the new materials, the notebooks classes. Such materials constitute pedagogical knowledge, knowledge for teach the "math for teach" as a professional reference teacher who teaches mathematics.
\end{abstract}

Keywords: mathematics to teach; mathematics for teach; textbook of mathematics; training of teachers who teach mathematics.

\footnotetext{
${ }^{1}$ Doutor em Educação pela Universidade de São Paulo. Livre Docente em Educação pela Universidade Federal de São Paulo. Professor do Programa de Pós-Graduação em Educação e Saúde na Infância e na Adolescência da UNIFESP. Coordenador do GHEMAT - Grupo de Pesquisa em História da Educação Matemática. Brasil. Email: ghemat.contato@gmail.com
} 


\section{Introdução}

Este texto analisa a emergência de saberes profissionais do professor dos anos iniciais escolares. Em específico, atém-se aos professores que ensinam matemática e a seus saberes profissionais. O texto descreve as transformações operadas na formação de professores que ensinam matemática a partir do estabelecimento de uma cultura do curso secundário, tendo por referências livros e manuais didáticos utilizados no Colégio Pedro II, Rio de Janeiro, desde tempos primeiros do Império. Aborda o protagonismo do estado de São Paulo na formação de professores a partir do início do período republicano. A problemática que norteia o presente estudo fixa atenção no processo de inclusão de cadernos de aulas como ingrediente da formação de professores que ensinam matemática, portadores do que é possível denominar "saberes para ensinar matemática" nos primeiros anos escolares. Tais saberes objetivados nos cadernos expressam a emergência de saberes profissionais do professor que ensina matemática. O ferramental teórico-metodológico considerado na análise tem em conta os estudos que têm sido sistematizadas pela Equipe de Pesquisa em História das Ciências da Educação (ERHISE) da Universidade de Genebra, na Suíça ${ }^{2}$.

\section{Os saberes: tema crucial para a profissionalização do professor}

A discussão sobre a formação de professores envolve, desde os primeiros tempos em que é pensada a sua institucionalização, no curso do século XIX, os saberes específicos para a profissão de ensinar. Que saberes deveriam possuir os profissionais da docência? Análises sobre a organização desses saberes mostram proximidade dos processos de sua elaboração em diferentes países (Borer, 2009). O que elas revelam? Que as dinâmicas de constituição dos saberes para a formação de professores no nível primário (os primeiros anos escolares) e do nível secundário (os anos escolares compreendidos pós-ensino primário e pré-ensino universitário) ligam-se à compreensão

de como se articulam de um lado os saberes constitutivos do campo profissional, no qual a referência é a "expertise" profissional ("saberes profissionais" ou "saberes para ensinar"); e, de outro, os saberes emanados dos campos disciplinares de referência produzidos pelas disciplinas universitárias (saberes disciplinares ou saberes concernentes aos "saberes a ensinar") (Borer, 2009, p. 42, aspas da autora)

Em termos ainda mais precisos, Hofstetter \& Schneuwly (2009) consideram tais saberes como constitutivos da formação docente. Ou seja, levam em conta que os "saberes a ensinar", são aqueles saberes considerados como objetos do trabalho do professor, e os "saberes para ensinar", os saberes que são as ferramentas do seu trabalho. Neste último caso, tratam-se principalmente de saberes sobre "o objeto" do trabalho docente (sobre os saberes a ensinar e sobre o aluno, o adulto, seus conhecimentos, seu desenvolvimento, as maneiras de aprender etc.), sobre as práticas de ensino (métodos, procedimentos, dispositivos, escolha dos

\footnotetext{
${ }^{2}$ Para maiores informações sobre esse grupo de pesquisa veja-se: https://cms.unige.ch/fapse/SSE/erhise/
} 
DOI: http://dx.doi.org/10.20396/zet.v25i2.8647053

saberes a ensinar, modalidades de organização e de gestão) e sobre a instituição que define o seu campo de atividade profissional (planos de estudos, instruções, finalidades, estruturas administrativas e políticas etc.) (2009, p. 19).

Em termos dos saberes específicos para ensinar, os saberes para a profissão da docência, tendo em conta o nível primário, o da formação de professores primários, historicamente tem-se dois modelos: o das escolas normais e o das escolas de nível superior que formam professores para atuarem nos primeiros anos escolares.

As escolas normais oferecem uma formação tanto geral como profissional. Expliquese: a formação geral refere-se a um leque de disciplinas ministradas em nível secundário; já a formação profissional liga-se a uma diminuta inserção de saberes vindos das cadeiras das ciências da educação, sobretudo a cargo do diretor escolar, uma espécie de mentor pedagógico do trabalho. No entanto, com o passar do tempo, ampliam-se os cuidados com a formação profissional, surgindo rubricas específicas para isso. No caso da formação dada no nível superior, tem-se nítida separação entre os saberes de formação geral e aqueles profissionais. Considerando-se os saberes de formação geral, eles são ministrados no curso secundário; assim, a formação em nível superior, lançando mão das ciências da educação, e suas cadeiras disciplinares, encarrega-se dos saberes profissionais (Borer, 2009).

Do ponto de vista do que mais interessa a este texto - tratar da evolução dos saberes envolvidos na formação de professores - cabe verificar as diferenças de trajetória desses saberes de acordo com cada um dos modelos: normal ou superior. Tendo em conta a formação dada pelas escolas normais, ao longo do tempo, ampliam-se os estudos, o número de anos de formação, com domínio dos saberes de formação geral, dada pelas disciplinas escolares, mesmo que, com o passar dos anos, tenha-se uma inserção progressiva dos saberes profissionais, dos "saberes para ensinar".

A análise da formação de professores para os primeiros anos escolares dada em nível superior, mostra que os saberes para o exercício docente se afirmam a partir de uma base de formação de cultura geral adquirida nos estudos secundários, sendo a formação profissional vinda dos estudos pedagógicos. Neles estão presentes os "saberes para ensinar", sobretudo nos ensinos de pedagogia teórica e prática, psicologia, ciências da educação, aos quais se ligam também as didáticas e metodologias das diferentes disciplinas escolares.

Em síntese, a formação de professores de níveis primário e secundário, relativamente aos saberes de sua formação diferem pelas referências colocadas historicamente. De parte dos professores para o curso primário garante-se no núcleo formativo para a profissão a presença dos "saberes para ensinar", elaboração onde vivamente participam as ciências da educação. Relativamente aos saberes para a formação dos professores do curso secundário, os "saberes para ensinar" emergem do próprio âmbito do "saber a ensinar". 
DOI: http://dx.doi.org/10.20396/zet.v25i2.8647053

\section{A formação de professores que ensinam matemática: livros do curso secundário}

Percorrendo, em particular, a história da formação de professores que ensinam matemática, no Brasil, tem-se que ler e escrever pelo método lancasteriano, as quatro operações e proporções; a língua nacional, elementos de geografia e princípios da moral cristã constituem referência de formação dos professores primários prescrita pela Lei n. 10, de 1835, da primeira escola normal brasileira, criada na Província do Rio de Janeiro, com duração efêmera de quatro anos de existência (Tanuri, 2000, p. 64). Assim, "as quatro operações e as proporções" constituem a matemática presente na formação dos futuros professores, nesta tentativa inicial de sistematização da formação docente para os primeiros anos escolares. Nenhuma referência aos saberes profissionais, aos "saberes para ensinar matemática". Trata-se de fazer o professorando adquirir os "saberes a ensinar": as quatro operações e as proporções.

A perspectiva de formação dos professores para o ensino primário manteve o cenário acima em boa parte do século XIX. Assim, tem-se para a matemática dos professorandos: o currículo de formação indicando rubricas a ensinar, oficializado nos programas. No entanto, com o passar do tempo, as necessidades de melhor formar os professores para trabalho nos primeiros anos escolares promovem uma sofisticação do currículo de formação desses profissionais, a exemplo do que ocorre internacionalmente. As mudanças no currículo de formação matemática se efetivam e têm a sua forma mais acabada na segunda metade do século XIX, em sua proximidade com a matemática ensinada no curso secundário. E, esta referência está associada aos livros utilizados no Colégio Pedro II, Rio de Janeiro, fundado em 1837, modelo para o curso secundário:

Os compêndios de matemática, adotados no Colégio-modelo - o Imperial Colégio de Pedro II - mostram-se como espaço das lições dadas pelo mestre, é o lugar de sistematização dos pontos que deverão ser sorteados nos exames. A própria ordem e organização desses pontos é parametrizada pelos livros. O trabalho pedagógico realizado ao longo do ano deve submeter-se à verificação de quanto os alunos têm quase que de cor o compêndio utilizado como referência para o curso (Valente, 2011, p. 35).

E esses compêndios, em boa medida, são as obras escritas por Cristiano Benedito Ottoni relativas à aritmética, à álgebra e à geometria, decalcadas de tratados franceses. Tais obras, utilizadas no Colégio Pedro II, espalham-se pelo Brasil constituindo base para a formação matemática dos aspirantes ao ensino superior, pela via dos exames preparatórios, bem como, textos para estudos dos exames finais das escolas normais (Valente, 2007). Assenta-se, desse modo, uma formação dada ao professor que irá ensinar matemática no curso primário semelhante àquela obtida por estudantes do curso secundário. Consolida-se uma ideia de formação via saberes a ensinar, "matemática a ensinar", distante das possibilidades de caracterizar uma formação específica, profissional, com ingredientes que contemplem uma formação que tenha em vista uma "matemática para ensinar". A base de formação do professor que ensinará matemática reafirma uma cultura do ensino secundário. 
DOI: http://dx.doi.org/10.20396/zet.v25i2.8647053

\section{A formação de professores para o curso primário: São Paulo como protagonista}

Em finais do século XIX, São Paulo assume o protagonismo na formação de professores. A riqueza acumulada da economia cafeeira e a política que leva à transformação do regime monárquico para a República são elementos fundamentais do contexto que dá ao estado esse destaque. Grupos escolares são criados, escolas de formação de professores e toda uma gama de inovações são comandadas pelos republicanos paulistas.

Seguindo o processo de consolidação de São Paulo como centro econômico do país, a expansão cultural e especificamente escolar do estado caminha a passos largos nos primeiros anos do novo regime republicano. A criação da Escola Politécnica, da Biblioteca Pública, do Mackenzie, do Instituto Butantã, da Escola de Farmácia, da Escola Superior de Agricultura de Piracicaba, da Faculdade de Medicina e dos primeiros ginásios públicos são testemunhos dessa expansão, conforme destaca Tanuri (1979, p. 77).

Na capital paulista, é criada a Escola Normal de São Paulo, por meio da Lei n. 130 de 25 de abril de 1880. A instituição vive, com essa lei, a sua terceira fase de existência. A partir daí, a Escola Normal tem vida longa, na formação de professores, transformando-se na famosa 'Escola Normal da Praça da República', posteriormente 'Instituto de Educação Caetano de Campos'?

As lideranças paulistas, os republicanos que buscam o protagonismo de São Paulo na condução dos rumos da educação, deparam-se, por esse tempo, com o problema da formação de professores para o ensino primário. É nítida a existência de uma cultura do curso secundário para essa formação. Alicerçada, sobretudo, nos compêndios e livros didáticos desse nível de ensino, pouco forma pedagogicamente os novos professores para o exercício da docência nos anos iniciais.

A essa situação de praticamente ausência de manuais e obras destinadas ao professor do curso primário, em tempos do Império ${ }^{4}$, constatam-se iniciativas de edição de livros didáticos e de um esforço dos reformadores republicanos do ensino paulista, de fazer publicar obras que possam, em suas páginas, orientar os professores na condução do trabalho pedagógico. Tudo em acordo com os ditames que as ciências da educação em voga

\footnotetext{
${ }^{3}$ Com o Decreto n. 3858, de 11 de junho de 1925, a Escola Normal da Capital passa a denominar-se Escola Normal da Praça da República. Vindo o Decreto 5303, de 24 de dezembro de 1931, seu nome muda para Instituto de Educação Caetano de Campos.

${ }^{4}$ Em realidade há livros didáticos editados desde, praticamente, o início do período imperial. A produção cresce e diversifica a quantidade de autores que escrevem textos para o curso primário. Exemplos dessas obras são arrolados nos textos de Zuin (2007) e Costa (2010). Os reformadores do ensino paulista, na verdade, não encontram, de fato, livros que estejam de acordo com as novas propostas para o ensino, "obras regionais", acessíveis à crescente população escolar.
} 
DOI: http://dx.doi.org/10.20396/zet.v25i2.8647053

preconizam. Trata-se de um tempo onde alastra-se internacionalmente a vaga intuitiva na educação 5 .

A historiadora da educação Rosa de Souza destaca, ao considerar a produção didática, a prioridade dada à adoção de obras nas escolas, escritas por professores envolvidos com a renovação do ensino em São Paulo. Nesse sentido, sobressaem educadores como Oscar Thompson, Arnaldo Barreto, João Kopke, Roca Dordal, René Barreto dentre vários outros. Souza salienta, também, o papel da "Revista de Ensino" como veículo de divulgação e debate da produção didática destinada a alunos e professores do ensino primário (Souza, 1998, p. 232).

Nessa trajetória de revisão dos livros e materiais para a formação dos futuros professores primários chega-se a uma regulamentação oficial, dada por Ato e Parecer que organizam tais referências ${ }^{6}$.

As obras e materiais analisados são classificados de modo diferente quanto à sua adoção nas escolas e compra pelo governo. Há os livros de leitura, que deverão oficialmente ser adotados. No caso dos compêndios e manuais, diz o Parecer:

Tratando-se de compêndios e manuais para o ensino mais ou menos dogmático de geografia, história, matemática, ciências físicas e naturais, disciplina gramatical etc. entende a comissão que a adoção oficial de tais livros é inconveniente ou mesmo nociva. [...] À vista do exposto, a comissão é de parecer que os livros classificados nesta seção podem, quando muito ser indicados ou recomendados aos professores de um e outro curso, sem alienação da faculdade de consultar outras obras, desde que o seu ensino fique subordinado aos limites dos programas oficiais (p. 255-256)

Considerando as referências para o ensino de matemática, há materiais presentes em duas classificações: a dos compêndios e manuais; e a dos cadernos, mapas e materiais de ensino.

No caso dos compêndios tem-se obras para o ensino de Aritmética, de Álgebra, de Geometria e de Trigonometria. Mesclam-se, grosso modo, dois tipos de livros. Inicialmente, há volumes já transformados em clássicos da bibliografia do ensino secundário e dos exames preparatórios, referenciados pelas indicações do Colégio Pedro II, do Rio de Janeiro, constituindo obras de origem francesa, para além dos textos de Ottoni, como já mencionado

\footnotetext{
${ }^{5}$ A partir da década de 1880 assiste-se à emergência de uma verdadeira contracultura pedagógica vinda com o movimento da pedagogia intuitiva. Muito antes disso, foram plantados os gérmens dessa modernidade educacional. Eles apontam para a não coerção dos alunos, para um modo diferenciado de conduzir a criança a seu estado adulto. Rousseau, Pestalozzi, Fröebel são autores que inspiram essa contracultura pedagógica, seus referentes mais importantes. As décadas finais do século XIX, assistem, nos países da Europa, nos EUA e ainda no Brasil, a circulação da vaga intuitiva como forma moderna de tratar as questões educacionais, inspirada pelos escritos desses clássicos autores (Valente, 2016).

${ }^{6}$ Diz o Ato: "O Secretario de Estado do Interior e da Justiça, tendo em vista o parecer da comissão encarregada da revisão dos livros escolares e com ele se conformando, resolve aprovar a classificação feita pela mesma comissão e adotá-la nas escolas preliminares e complementares do Estado (Ato de 28 de abril de 1904 e Parecer de 27 de fevereiro de 1904, transcritos da página 253 a 262, da Revista de Ensino, n. 2, Ano III, 1904).
} 
DOI: http://dx.doi.org/10.20396/zet.v25i2.8647053

anteriormente. Esse é o caso, por exemplo, dos Elementos de Geometria de Lacroix, dos Elementos de Geometria de Legendre, da Álgebra de Bourdon, da Álgebra de Guilmin ${ }^{7}$. A esses manuais perfilam-se textos de professores declaradamente partidários do positivismo de Comte. Como exemplo, desse segundo tipo de obras, classificadas pela comissão, estão os livros: Arithmetica de Aarão Reis; Elementos de Geometria de Clairaut, traduzidos pelo professor José Feliciano ${ }^{8}$. No que toca à Trigonometria está presente no parecer a obra Elementos de Trigonometria de Francisco Furtado Mendes Vianna, professor da $2^{\mathrm{a}}$. Escola Complementar. Junto a esse livro didático, também são indicados os textos de Lacroix e de Arthur Thiré (Valente, 2011). Ao lado dessas clássicas obras, que constituem referência da "matemática a ensinar", figuram novos impressos pedagógicos, novas referências para a prática pedagógica do professor primário.

\section{A formação de professores que ensinam matemática: a emergência de saberes profissionais}

Para além dos livros de leitura e dos compêndios e manuais há, na classificação elaborada pela comissão, outro grupo, que é objeto de análise: "cadernos, mapas e materiais de ensino". Neste caso, também, aqueles que são classificados, passam a ser adotados oficialmente. Tal grupo analisado (cadernos e mapas etc.) reúne o que a comissão designou por materiais "para as aulas de caráter prático". Entenda-se: material destinado à prática pedagógica do professor.

Com essa premissa, para os materiais relativos ao ensino de matemática, segue o parecer indicando que: “Os cadernos de arithmetica serão fornecidos pela escola, cabendo aos professores distribuí-los e arrecadá-los diariamente. Os problemas serão resolvidos, não nas folhas em branco dos cadernos, mas nas lousas de cada aluno (p. 256)".

Em sua grande maioria, os cadernos constituem produções dos reformadores do ensino normal paulista, alguns deles, ex-alunos da Escola Normal de São Paulo: Oscar Thompson, Romão Puiggari, Arnaldo Barreto, Roca Dordal, Carlos Reis. Também estão referenciados na lista, materiais sob a designação "coleção de cadernos da Escola

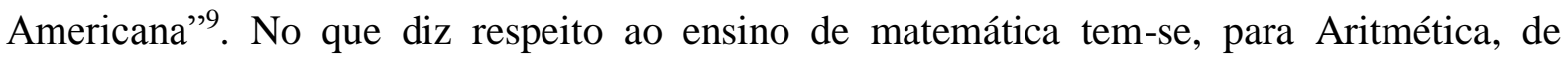
acordo com o texto do parecer, em ordem decrescente de prioridade e importância: 1.

\footnotetext{
${ }^{7}$ Um estudo detalhado dessas obras para o ensino secundário é feito por Valente (2007).

8 José Feliciano de Oliveira (1868-1962) é nomeado em 1893, professor de Astronomia e de Mecânica Celeste na Escola Normal de São Paulo. Positivista, tem ampla atuação no magistério da Escola, onde atua, também, como substituto das cadeiras de Português e de Latim. Defensor das ideias positivistas é responsável, em 1892, pela tradução da Geometria de Clairaut, uma das obras da biblioteca positivista de Augusto Comte (Silva, 1988).

${ }^{9}$ Compreende-se essa referência, mais adiante neste estudo, quando se mostra que a Escola Americana, fundada na Capital, em 1870, graças à iniciativa de missionários presbiterianos, constitui uma espécie de padrão para a renovação educacional. Nela, reformadores paulistas buscam orientações para as mudanças no ensino público (Tanuri, 1979, p. 82).
} 
DOI: http://dx.doi.org/10.20396/zet.v25i2.8647053

Coleção de cadernos - Aritmética Escolar, Roca ${ }^{10}$; 2. Coleção de cadernos da Escola Americana ${ }^{11}$; 3. Coleção de cadernos Arnaldo Barreto; 4. Contador Infantil, H. Galvão. Ao final dessa lista, uma nota: "O ensino desta matéria deverá começar pelo emprego das Cartas de Parker"12 (p. 262).

Essa nova produção didática - os cadernos recomendados oficialmente - apresentam o desenvolvimento dos conteúdos a serem ministrados numa ordem didático-pedagógica própria aos tempos da pedagogia da intuitiva. Não tem a organização clássica da ordem lógica dos conteúdos das aritméticas referenciadas pelo ensino secundário. Organizam e orientam o trabalho do professor numa sequência consoante com as ideias pedagógicas herdeiras de Pestalozzi, interpretadas pelos reformadores paulistas. Têm o caráter de manuais de ensino para o professor. Portam saberes que os professores têm que dominar para o ofício docente, saberes para ensinar, matemática para ensinar, aritmética para ensinar.

Em síntese, as referências didáticas colocadas no parecer de 1904 permitem vislumbrar o processo que está em curso pelos reformadores, de alteração da marcha do ensino e, em particular, da Matemática, nas escolas paulistas por meio da categorização das referências didáticas para o trabalho dos professores. Essas referências preservam o saber a ensinar, a "matemática a ensinar" colocada nos manuais de origem francesa, os considerados livros didáticos desse tempo, utilizados no ensino secundário; mas, incluem uma nova gama de saberes: aqueles da "matemática para ensinar", contida nos cadernos, em especial, nos cadernos de aritmética. Tais cadernos, e mesmo os materiais e dispositivos pedagógicos indicados, objetivam, dão visibilidade a um saber pedagógico para o professor que ensina matemática, uma "matemática para ensinar".

\section{Conclusões}

Na década final do século XIX, com a criação dos grupos escolares - invenção paulista para a organização do ensino primário - e sob a égide do ensino intuitivo movimento internacional que prega uma verdadeira revolução pedagógica; e, ainda, sob o modelo da escola graduada, há uma modificação no panorama da formação matemática de professores para o curso primário. Para o que interessa a este estudo, os professores que ensinam matemática agregam as contribuições vindas das ciências da educação, da pedagogia intuitiva, pelas mãos dos reformadores do ensino paulista. Novas referências são incorporadas por dirigentes da instrução pública de São Paulo que as transformam em leis e decretos para o ensino, produzindo mudanças em obras didáticas, em manuais para

\footnotetext{
10 Os cadernos de Roca podem ser vistos no endereço https://repositorio.ufsc.br/handle/123456789/1769/ discover?query=Roca\&submit=Ir

${ }^{11}$ Estudos sobre a Escola Americana e seus materiais poderão consultados no trabalho de Pinheiro (2013).

${ }^{12}$ A pesquisa de doutoramento de Lopes da Silva (2008) arrola, em anexo de sua tese, todas as Cartas de Parker, material que tem importância fundamental na elaboração dos discursos sobre a renovação do ensino de matemática na escola primária paulista. Para além de Silva (2008) há vários estudos sobre esse dispositivo pedagógico como, por exemplo, os trabalhos de Valente (2014), Portela (2014) e Pinheiro \& Valente (2015).
} 
DOI: http://dx.doi.org/10.20396/zet.v25i2.8647053

professores e em toda sorte de orientações didático-pedagógicas. Esse processo irá lapidar "saberes para ensinar matemática" a estarem presentes na formação inicial de professores e, ainda, no que hoje denominamos formação continuada dos docentes. Ao que tudo indica, sedimenta-se um discurso que sistematiza contribuições vindas de referências já de há muito existentes no horizonte pedagógico, mas que somente nas décadas finais do século XIX ganham os sistemas de ensino. Tem-se sobretudo a presença de Pestalozzi e seus seguidores e divulgadores. Assim, desde as duas décadas finais do século XIX o "saber para ensinar matemática", ou a ciência da "matemática para ensinar" nos primeiros anos escolares envolve o domínio não só dos algoritmos ligados às operações fundamentais da aritmética, ou mesmo conhecimentos sobre a geometria euclidiana. O "saber para ensinar" matemática constitui-se a partir desse tempo como a ciência de práticas intuitivas para a docência dos primeiros passos da aritmética e da geometria. Tal "saber para ensinar" penetra na cultura escolar e deixa-nos marcas até hoje presente nas escolas. "Eu trabalho primeiro no concreto" é expressão comumente utilizada pelos professores que indica a filiação longínqua que esse saber traz desde os tempos em que se afirma a chamada vaga intuitiva da pedagogia. Ela estabelece que o primeiro conhecimento se dá a partir dos sentidos, da relação dos sentidos com as formas concretas/empíricas da vida cotidiana ${ }^{13}$.

Algo diferente ocorre com o ensino secundário comparativamente a esta trajetória do primário. Se é fato que ao longo do tempo é construída e bem definida uma profissão - a de professor dos anos iniciais escolares - demarcada por saberes para ensinar as diferentes matérias, no curso secundário isso parece ser algo problemático. Diferentemente da sua articulação com as ciências da educação, a matemática do curso secundário retira, historicamente, do próprio conteúdo matemático o saber profissional para a atuação de professores nesse nível escolar.

Por fim, é possível considerar que a referência profissional, a especialidade do professor dos primeiros anos escolares, do professor primário, no decorrer da história, liga-se diretamente aos "saberes para ensinar". E, no caso da matemática, da "matemática para ensinar". Não caberia dizer que tais docentes, no caso do ensino de matemática para os primeiros anos escolares, sejam "experts" no cálculo aritmético, ou na ciência da geometria euclidiana. Esses saberes são o objeto do trabalho docente, são "saberes a ensinar", "matemática a ensinar", que precisam de ferramentas, de saberes para ensiná-los. Noutros termos, há necessidade de uma "matemática para ensinar". Essa é a referência profissional desse docente, sua "expertise", tendo em vista as finalidades da escola numa dada época, as concepções sobre ensino e aprendizagem da matemática, os seus métodos, procedimentos, dispositivos e escolhas do que ensinar, os modos de organização e de gestão da escola e da sala de aula, os planos de ensino e toda uma sorte de determinações oficiais em meio a estruturas políticas e administrativas.

\footnotetext{
${ }^{13}$ Leia-se o texto de Nacarato (2005).
} 


\section{Referências}

DOI: http://dx.doi.org/10.20396/zet.v25i2.8647053

Borer, V. L. (2009). Les savoirs: un enjeu crucial de l'institutionnalisation des formations à l'enseignement. In Rita Hofstetter et al. Savoirs en (trans)formation - Au cour des professions de l'enseignement et de la formation (pp. 41-58). Bruxelles: Éditions De Boeck Université.

Costa, D. A. (2010). A Aritmética escolar no ensino primário brasileiro: 1890-1946. Tese de Doutorado em Educação Matemática. São Paulo: Pontifícia Universidade Católica de São Paulo (Programa de Pós-Graduação em Educação Matemática).

Hofstetter, R., \& Schneuwly, B. (2009). Introduction - Savoirs en (trans)formation - Au coeur des professions de l'enseignement et de la formation. In R. Hofstetter \& B. Schneuwly (Éds.). Savoirs en (trans)formation - Au cour des professions de l'enseignement et de la formation (pp. 7-40). Bruxelles: Éditions De Boeck Université.

Lopes da Silva, M. C. (2008). A presença da matemática na formação do professor do ensino primário no estado de São Paulo, no período de 1890 a 1930. Retirado em 19 de setembro, 2016, de: http://livros01.livrosgratis.com.br/cp074998.pdf.

Nacarato, A. M. (2005). Eu trabalho primeiro no concreto. São Paulo. SBEM-SP: Revista de Educação Matemática, 9 (9-10), 1-6.

Pinheiro, N. V. L. (2013). Escolas de práticas pedagógicas inovadoras: intuição, escolanovismo e matemática moderna nos primeiros anos escolares. Retirado em 19 de setembro de 2016 de: https://repositorio.ufsc.br/handle/123456789/104911.

Pinheiro, N. V. L., \& Valente, W. R. (2015). Chega de decorar a tabuada! As Cartas de Parker e a árvore do cálculo na ruptura de uma tradição. Retirado em 19 de setembro, 2016, de: https://repositorio.ufsc.br/handle/123456789/160388.

Portela, M. S. (2014). As Cartas de Parker na matemática da escola primária paranaense na primeira metade do século XX: circulação e apropriação de um dispositivo didático. Retirado em 19 de setembro, 2016, de: https://repositorio.ufsc.br/handle/123456789/128465.

Silva, N. F. L. (1988). A ideia de educação em José Feliciano de Oliveira. Dissertação de Mestrado em Educação. Campinas, SP: UNICAMP - Faculdade de Educação, 1988.

Souza, R. F. (1998). Templos de Civilização: a implantação da Escola Primária Graduada no Estado de São Paulo (1890-1910). São Paulo: Fundação Editora da UNESP.

Tanuri, L. M. (2000). História da formação de professores. Revista Brasileira de Educação, $14,61-88$.

Valente, W. R. (2007). Uma história da matemática escolar no Brasil, 1730-1930 (2a. ed.). São Paulo: Editora Annablume/FAPESP.

Valente, W. R. (2011). A matemática na formação do professor do ensino primário - São Paulo, 1875-1930. São Paulo: Editora Annablume/FAPESP. 
DOI: http://dx.doi.org/10.20396/zet.v25i2.8647053

Valente, W. R. (2014). Lourenço Filho e o moderno ensino de aritmética: produção e circulação de um modelo pedagógico. História da Educação. Porto Alegre: Asphe, UFRGS, 18 (44), 61-77.

Valente, W. R. (2016). Os movimentos da matemática na escola. Pensar a Educação em Revista. Retirado 19 de setembro, 2016, de: http://www.pensaraeducacaoemrevista.com.br/vol_2/vol_2_no_2_full.html.

Zuin, E. S. L. (2007). Por uma nova Arithmetica: o Sistema Métrico Decimal como um saber escolar em Portugal e no Brasil oitocentistas. Tese de Doutorado em Educação Matemática. São Paulo: Pontifícia Universidade Católica de São Paulo (Programa de Estudos Pós-Graduados em Educação Matemática). 